- to expand it. After launching the Energy Initiative in 2006, Moniz and his MIT colleagues produced a series of reports on topics including geothermal energy, the electric grid, coal and the nuclear fuel cycle.

Most prominent, and controversial, was a 2011 report on natural gas. It highlighted the possibility that hydraulic-fracturing technologies could expand US gas production, displacing dirtier-burning coal in electricity generation and thus reducing US greenhousegas emissions. Moniz's enthusiasm for natural gas worries some environmentalists, who are concerned about the air and water pollution resulting from its extraction. But gas has indeed helped to reduce emissions: in 2011, US greenhouse-gas emissions were nearly $8 \%$ below those in the peak year of 2007.

Talking to Nature last July, Moniz laid out his energy-policy goals for the current decade: reduce demand; substitute gas for coal; and innovate to reduce the cost of low-carbon technologies for areas such as nuclear power, renewable energy and capturing and sequestering carbon dioxide from fossil-fuel combustion. Moniz noted how basic research on hydraulic fracturing, funded by the Department of Energy and dating back to the 1980s, is now paying off. "If you came out with a policy to reduce coal use by a third, all hell would break loose politically. But the market did it by itself, and you don't hear anybody complaining," he said. "To me, the lesson from that is the importance of innovation to reduce the costs of the zero-carbon options."

The key, he said, is to put in place a longterm plan to reduce greenhouse-gas emissions once gas has replaced coal. "Gas is a bridge, but it has to be a bridge to somewhere," he said.

\title{
Cholesterol limits lose their lustre
}

\section{Revised guidelines for heart health are set to move away from target-based approach.}

\section{BY HEIDI LEDFORD}

S oon after Joseph Francis learned that his levels of 'bad' LDL cholesterol sat at twice the norm, he discovered the shortcomings of cholesterol-lowering drugs - and of the clinical advice guiding their use. Francis, the director of clinical analysis and reporting at the Veterans Health Administration (VA) in Washington DC, started taking Lipitor (atorvastatin), a cholesterol-lowering statin and the best-selling drug in pharmaceutical history. His LDL plummeted, but still hovered just above a target mandated by clinical guidelines. Adding other medications had no effect, and upping the dose of Lipitor made his muscles hurt - a rare side effect of statins, which can cause muscle breakdown.

So Francis pulled back to moderate Lipitor doses and decided that he could live with his high cholesterol. Later, he learned that other patients were being aggressively treated by doctors chasing stringent LDL targets. But Francis found the science behind the target guidelines to be surprisingly ambiguous. "You couldn't necessarily say lowering LDL further was going to benefit the patient," he says.

The standard advice may soon change. For the first time in more than a decade, the US National Heart, Lung and Blood Institute is revising the clinical guidelines that shaped Francis's treatment (see 'How low can you go?'). Expected to be released later this year, the fourth set of guidelines, called ATP IV, has been drawn up by an expert panel of 15 cardiologists appointed by the institute. The guidelines will set the tone for clinical practice in the United States and beyond, and will profoundly influence pharmaceutical markets. They will also reflect the growing debate over cholesterol targets, which have never been directly tested in clinical trials.

"We can't just assume that modifying the risk factor is modifying risk," says Harlan Krumholz, a cardiologist at Yale University in New Haven, Connecticut. "We've been burned so many times in the past decade by that assumption."

Since 2002, when ATP III called on doctors to push LDL levels below set targets, the

"We can't just
assume that
modifying the
risk factor is
modifying risk."
concept of low cholesterol has become synonymous with heart health. Patients brag about their cholesterol scores, physicians joke about adding statins to drinking water, and some hospitals reward doctors when patients hit cholesterol targets.

In 2011, US doctors wrote nearly 250 million prescriptions for cholesterol-lowering drugs, creating a US\$18.5-billion market, according to IMS Health, a health-care technology and information company based in Danbury, Connecticut. "The drug industry in particular is very much in favour of target-based measures," says Joseph Drozda, a cardiologist and director of outcomes research at Mercy Health in Chesterfield, Missouri. "It drives the use of products."

ATP III reflected a growing consensus among physicians that sharply lowering cholesterol would lessen the likelihood of heart attacks and strokes, says Richard Cooper, an epidemiologist at the Loyola University of Chicago Stritch School of Medicine in Illinois, who served on the committee that compiled the guidelines. The committee drew heavily on clinical data, but also took extrapolations from basic research and post hoc analyses of clinical trials. LDL targets were set to be "less than" specific values to send a message, Cooper says. "We didn't want to explicitly say 'the lower the better' because there wasn't evidence for that," he says. "But everybody had the strong feeling that was the correct answer."

By contrast, the ATP IV committee has pledged to hew strictly to the science and to focus on data from randomized clinical trials, says committee chairman Neil Stone, a cardiologist at Northwestern University School of Medicine in Chicago. If so, Krumholz argues, LDL targets will be cast aside because they have never been explicitly tested. Clinical trials have shown repeatedly that statins reduce the risk of heart attack and stroke, but lowering LDL with other medications does not work as well. The benefits of statins may reflect their other effects on the body, including fighting inflammation, another risk factor for heart disease.

Krumholz's scepticism is rooted in experience. In 2008 and 2010, the Action to Control Cardiovascular Risk in Diabetes (ACCORD) clinical trial challenged dogma when it

\section{HOW LOW CAN YOU GO?}

US guidelines set by the Adult Treatment Panel (ATP) have gradually lowered acceptable levels for LDL 'bad' cholesterol, while shifting focus to prevention in patients at risk of a heart attack.

\begin{tabular}{l|c|c|} 
Name & Year & $\begin{array}{c}\text { LDL target for people with } \\
\text { the highest risk of heart } \\
\text { attack }\left(\mathbf{m g ~ d L}^{-1}\right)\end{array}$ \\
\hline ATP I & 1988 & $\leq 130$ \\
ATP II & 1993 & $<130$ \\
ATP III & 2002 & $<100$ \\
$\begin{array}{l}\text { ATP III } \\
\text { (update) }\end{array}$ & 2004 & $<70$ \\
\hline
\end{tabular}


reported that lowering blood pressure or blood sugar to prespecified targets did not reduce the risk of heart attack or stroke. In the case of blood sugar, the risks were worsened. The trial demonstrated the folly of assuming that risk factors must have a causal role in disease, says Robert Vogel, a cardiologist at the University of Colorado, Denver. "Short people have a higher risk of heart disease," he says. "But wearing high heels does not lower your risk."

Jay Cohn, a cardiologist at the University of Minnesota Medical School in Minneapolis, also worries that the focus on LDL levels offers up the wrong patients for statin therapy. Most of those who have a heart attack do not have high LDL, he notes. Cohn advocates treating patients with statins based on the state of health of their arteries, as revealed by noninvasive tests such as ultrasound. "If your arteries and heart are healthy, I don't care what your LDL or blood pressure is," he says.

Not all cardiologists want to abolish LDL targets. Indeed, Seth Martin, a fellow in cardiology at Johns Hopkins University School of Medicine in Baltimore, Maryland, believes that ATP IV should reduce LDL targets further. The simplicity of targets has helped to deliver an important public-health message, he says, and motivated many patients to get the statin therapy that he believes they need. "Just to throw that out the window doesn't seem like the ideal scenario."

Whatever the decision, the pharmaceutical industry will be watching closely, says Donny Wong, an analyst at Decision Resources, a market-research company based in Burlington, Massachusetts. Although most statins are off patent, the big pharmaceutical companies are racing to bring the next LDL-lowering drug to market. In particular, millions of dollars have been poured into drugs that inhibit a protein called PCSK9, an enzyme involved in cholesterol synthesis. This approach lowers LDL but has not yet been shown to reduce heart attacks or strokes.

Francis expects the new guidelines to relax the targets. He and his colleagues decided last autumn to change the VA's own clinical standards, so that they no longer rely solely on an LDL target but instead encourage doctors to prescribe a moderate dose of statin when otherwise healthy patients have high LDL cholesterol. The ATP IV guidelines will take a similar approach, he speculates, noting that the VA consulted several outside experts who are also serving on the ATP committee.

Despite an increasingly vegetarian diet, Francis's cholesterol has not budged. "Sometimes I want to call my physician and say, 'Don't worry about that target," he says. "It's going to be changing very soon." -

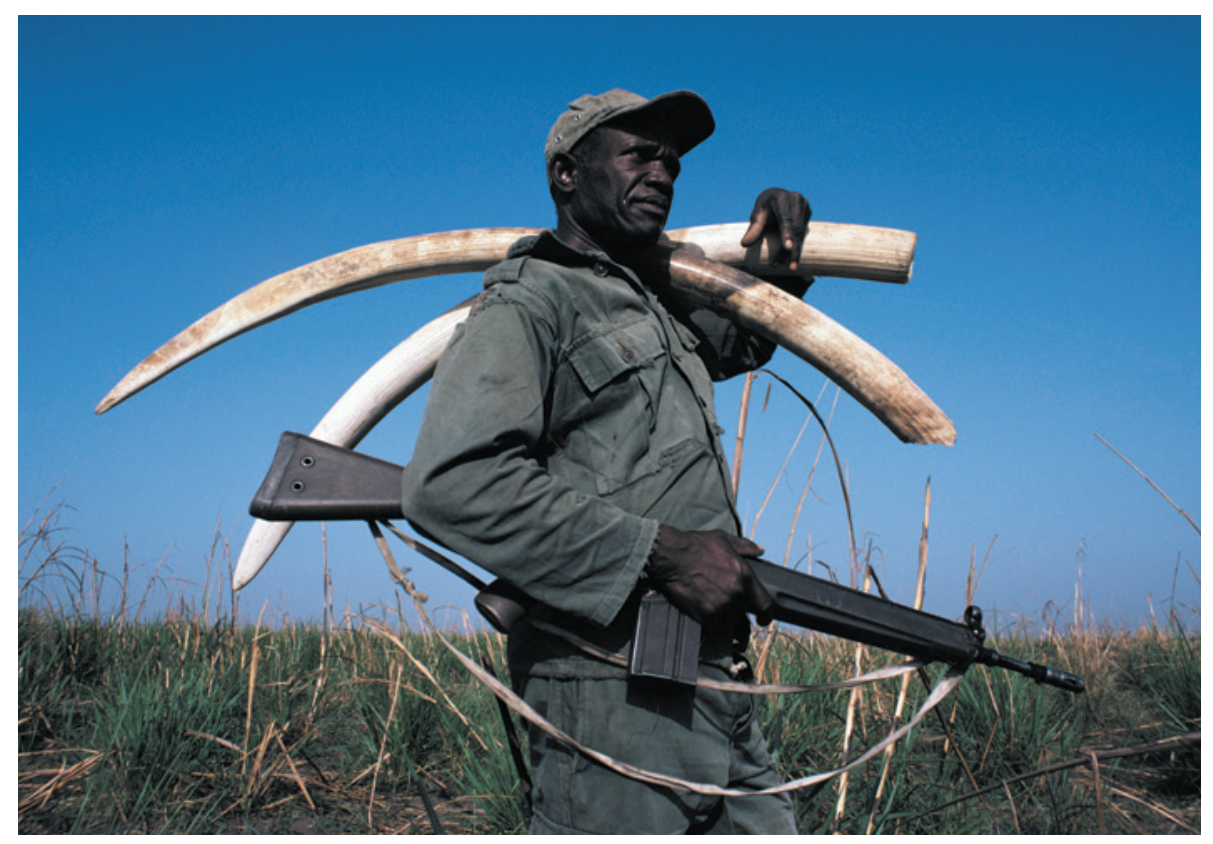

Guards in Garumba National Park, Democratic Republic of Congo, are working to stamp out poaching,

CONSERVATION

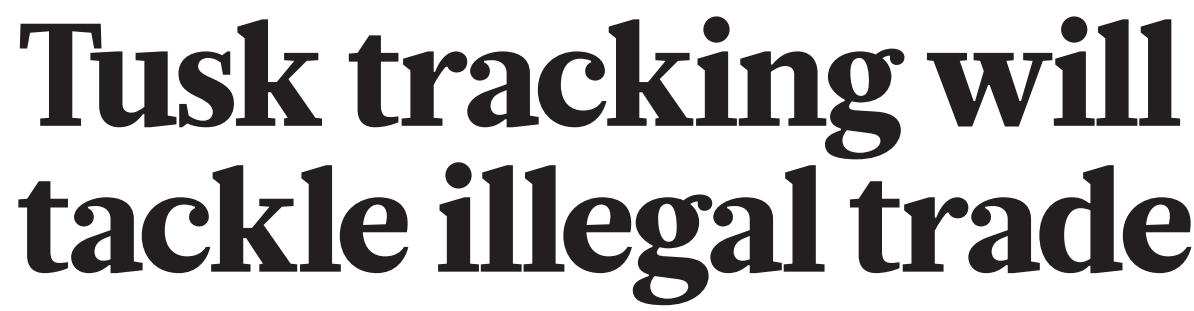

\section{Forensic testing of seized ivory could track down poachers.}

\section{BY DANIEL CRESSEY}

I nternational treaties meant to protect elephants are not working. Researchers estimate that tens of thousands of African elephants are now being killed by poachers each year, from a total wild population of around 400,000.

"It doesn't take much math to show we have a serious, urgent problem," says Samuel Wasser, director of the Center for Conservation Biology at the University of Washington in Seattle.

The only way to catch the people who are slaughtering the elephants is to redouble efforts to track illegal ivory back to its source. That is the stark message that Wasser and others will deliver to policy-makers in Bangkok next week, at the triennial conference of the parties to the Convention on International Trade in Endangered Species of Wild Fauna and Flora (CITES; see 'Candidates for protection').

Nearly 39,000 kilograms of illegal ivory were traded worldwide in 2011, more than at any other time in the 16-year history of the Elephant Trade Information System (ETIS), which tracks the ivory trade for CITES. Another CITES programme, Monitoring the Illegal Killing of Elephants, will report at the meeting that between $3.5 \%$ and $11.7 \%$ of the total African elephant population was killed by poachers in 2011 - the worst year for illegal killing since the programme began collecting data in 2002.

Those on the ground in Africa predict that, once the data are all in, the figures for 2012 will be even worse. The trade is being driven by the high prices that ivory now commands: about US $\$ 1,600$ per kilogram in the Far East, according to the Born Free Foundation, a wildlife charity based in Horsham, UK. But many fear that attempts to stem the demand now although crucial - may come too late.

"We're really at a tipping point, I think," says George Wittemyer, an ecologist at Colorado State University in Fort Collins, who studies elephants in the Samburu National Reserve in Kenya. "We're seeing declines in the species as a whole and we're seeing poaching spread into what were once untouchable safe havens."

Poachers in Samburu are also switching focus from males to older females and killing entire social groups, says Wittemyer.

Scientists argue that an international drive to trace seized ivory back to its origins is urgently needed, so that authorities can curb poaching before elephant populations collapse. 